\title{
Data on FTIR spectra of mixtures of sodium valproate (VPA) and histones H1 and
} H3.

Benedicto de C. Vidal ${ }^{1}$, Maria Luiza S. Mello*1

\section{ABSTRACT}

Valproic acid/sodium valproate (VPA), a drug primarily used for treatment of seizure disorders, is recognized as an efficient epigenetic agent, inducing inhibition of histone deacetylases, promoting changes in the methylation status of DNA and histones, and affecting chromatin structure. In addition to these epigenetic effects, molecular affinity of VPA for histone $\mathrm{H} 1$ has been proposed based on thermal denaturation, fluorescence spectroscopy and circular dichroism assays. VPA interactions with DNA and histones using Fourier transform infrared (FTIR) microspectroscopy and high-performance polarization microscopy that are not related to the effects promoted on epigenetic markers have been recently explored. Data in this article provide supplementary information for a better understanding of the resulting FTIR spectra for mixtures of VPA and histones $\mathrm{H} 1$ and $\mathrm{H} 3$ and of the potential effect of VPA directly on histones that has been reported in the literature.

Keywords: FTIR; Histones; Pharmacology; Sodium valproate (VPA).

\section{PRIOR PUBLICATIONS}

VIDAL, B. C.; MELLO, M. L. S. Sodium valproate (VPA) interactions with DNA and histones. Int J Biol Macromol 163:219-231, 2020. DOI: 10.1016/j.jijbiomac.2020.06.265.

\footnotetext{
${ }^{1}$ Universidade Estadual de Campinas, Instituto de Biologia, Campinas, SP, Brazil.mlsmello@unicamp.br.
} 


\section{DATA IMPORTANCE}

- Present data indicate VPA effects other than those usually affecting epigenetic markers on histones;

- These data provide indication of VPA interaction with histone molecules;

- Present data expand the understanding of the pharmacological potential of VPA;

- Cell Biologists, chemists and pharmacologists can benefit from these data.

\section{MATERIALS AND METHODS}

\section{Materials}

Valproic acid-sodium salt (VPA) (P4543, Sigma ${ }^{\circledR}$, St. Louis, MO, USA) and calf thymus $\mathrm{H} 1$ (Code 382150, Merck/Millipore, Billerica, MA, USA) and histone H3 (Code 11034758001, Roche, Mannheim, Germany/Sigma-Aldrich ${ }^{\circledR}$ ) were used. Ten- $\mu \mathrm{L}$ drops of VPA were dissolved in Milli-Q water at concentrations of $20 \mathrm{mM}$ and $40 \mathrm{mM}$ and then dripped on glass slides. Next, the preparations were left in the refrigerator overnight and then dried at $37^{\circ} \mathrm{C}$ for one to three hours before examination. Ten- $\mu \mathrm{L}$ drops of a solution of $5 \mathrm{mg}$ of histone $\mathrm{H} 1$ dissolved in $84 \mu \mathrm{L}$ of Milli-Q water and of a solution of $2 \mathrm{mg}$ of histone $\mathrm{H} 3$ dissolved in $69 \mu \mathrm{L}$ of Milli-Q water were treated similarly to the VPA preparations. The same process was applied to VPA-histone $\mathrm{H} 1$ and VPA-histone $\mathrm{H} 3$ mixtures ( $5-\mu \mathrm{L}$ each). The samples dripped on slides formed small dried hemispheres (drop-casting samples) that gradually dried from the periphery to the center of the preparation, forming concentric circles ("the coffee-ring effect") (DEEGAN et al., 1997) and that were examined at an ambient relative humidity $<70 \%$ at $27^{\circ} \mathrm{C}$ at their periphery and central region.

\section{Methods}

Attenuated total reflectance (ATR) Fouriertransform infrared spectra were automatically obtained using an Illuminat IR $\|^{\text {TM }}$ microspectroscope (Smiths Detection, Danbury, $\mathrm{CT}$, USA) equipped with a liquid-nitrogen cooled mercury-cadmium-telluride detector and with Grams/Al 8.0 software for spectroscopy (Thermo
Electron Corporation, Waltham, MA, USA), and connected to an Olympus BMX-51 microscope (Olympus America, Center Valley, PA, USA). The ATR diamond objective magnification used was equal to $36 \mathrm{x}$. The equipment resolution was equal to $4 \mathrm{~cm}^{-1}$. The measurement site was a square of $25 \mu \mathrm{m}$ per side. Each spectral profile was generated from 64 scans over the range of 4000 to $650 \mathrm{~cm}^{-1}$. The baseline correction that used four fitting points and level-plus-zero conditions as applied to each spectral profile was provided following Grams/Al 8.0 software indications. Each raw IR spectrum contains all of the information in one time-domain signal.

The data were collected during 2019-2020. The data source location was at the University of Campinas (Unicamp), Institute of Biology, Campinas, Brazil (latitude: -22.8203482; longitude: -47.0700119).

\section{DATA DESCRIPTION}

The information here presented contains FTIR data (Figures 1-4) supplementing a report on interactions of sodium valproate (VPA) with DNA and histones that were studied using highperformance polarization microscopy and ATR FTIR microspectroscopy (VIDAL; MELLO, 2020). All the spectral curves shown in Figures 1-4 are furnished as raw spectra that were provided directly by the equipment using the Fourier transform mathematical process. Raw FTIR spectra of VPA (Figures 1a, b), VPA-histone H1 mixtures and respective histone control (Figures 2a-e, 3a-e) and of a VPA-histone H3 mixture and respective histone control (Figures $4 a-c$ ) are shown to demonstrate overall consistency in spectral signature profiles but variability in band 
peak intensities and in some band peak frequencies within each group under consideration. The band peak component at $\sim 1550 \mathrm{~cm}^{-1}$ is the frequency of the maximal band peak of VPA (Figure 1). Absorbances at this frequency contributes to a band contained within the wavenumber edges $1580 \mathrm{~cm}^{-1}$ and $1480 \mathrm{~cm}^{-1}$ in histone $\mathrm{H} 1$ and $\mathrm{H} 3$ controls (Figures 2 and 4). The frequency variability detected in the raw spectra of films of VPA-histone $\mathrm{H} 1$ and VPA- histone $\mathrm{H} 3$ mixtures and respective histone controls is especially evident in the band peaks assigned to amide I and amide II (Figures 2a-e, 4ac). Frequency variability is also evident in the most intense band peak of the spectra of the VPAhistone $\mathrm{H} 1$ mixtures and histone $\mathrm{H} 1$ control, that is positioned at $1088-1078 \mathrm{~cm}^{-1}$ (Figures 3a-c, e). All these pure raw FTIR spectral curves were used for the estimation of the averaged spectral profiles reported elsewhere.

Figure 1. Raw FTIR spectral curves of VPA in drop-casting preparations. A detail from (a) at the $1700-1250 \mathrm{~cm}^{-1}$ wavenumber window is shown in (b).

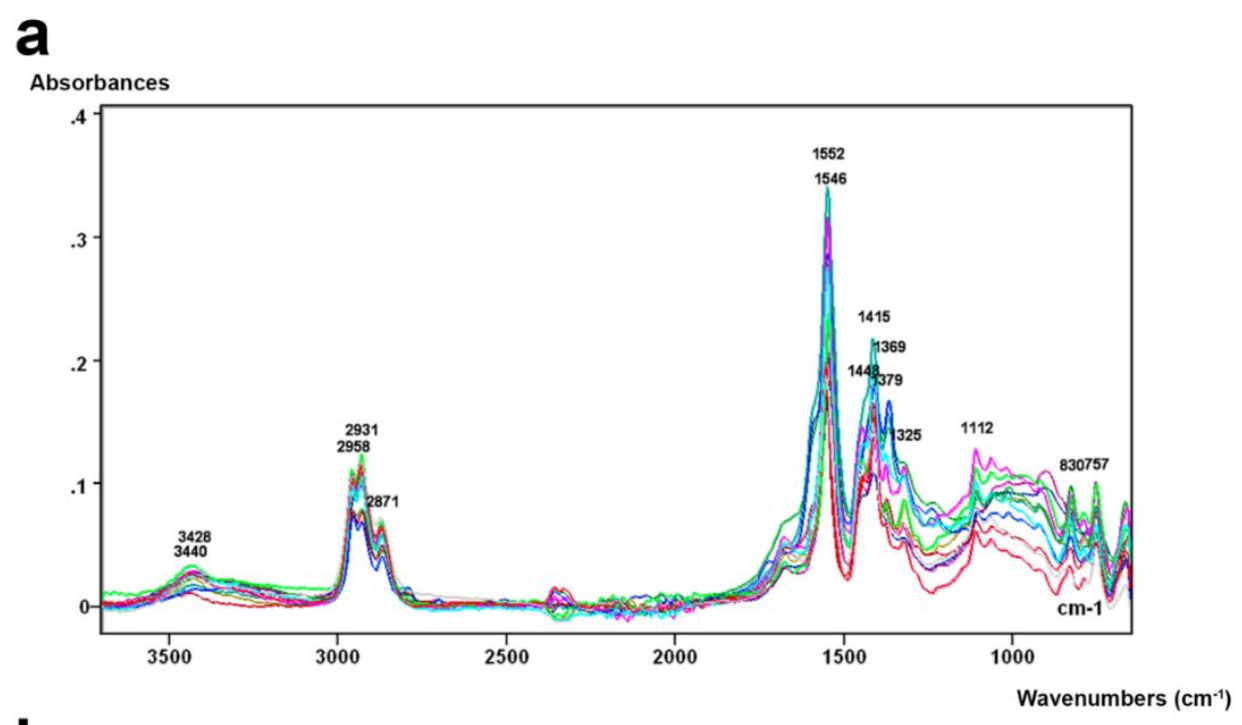

b

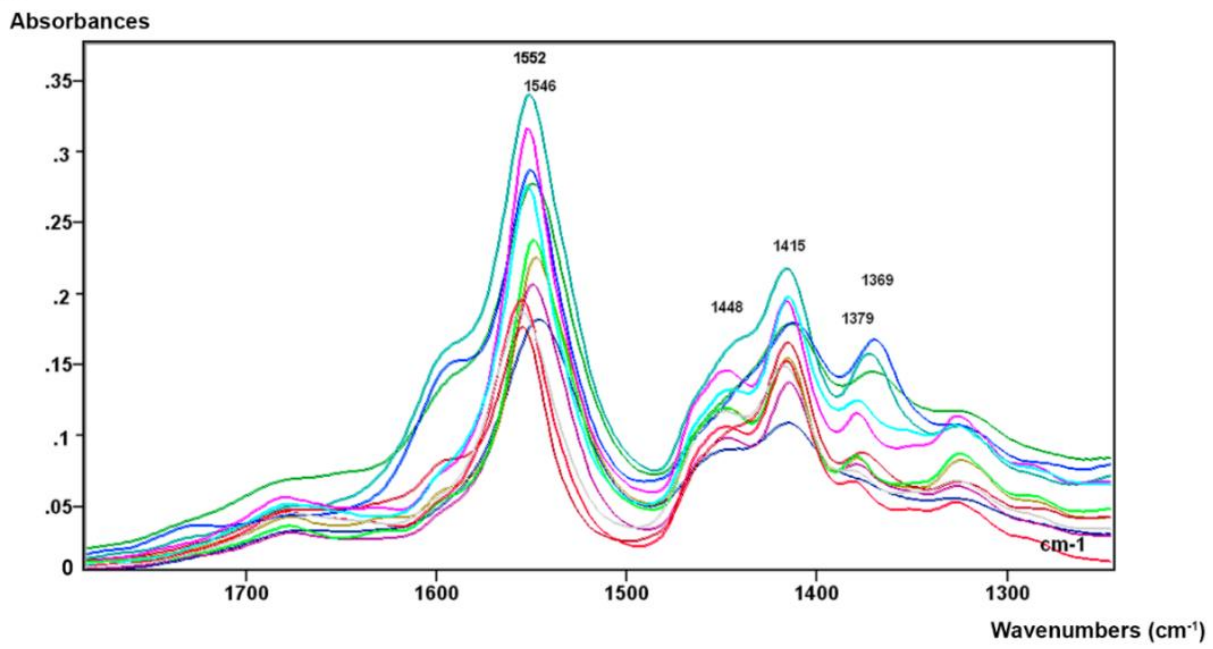


Figure 2. Raw FTIR spectral curves of histone $\mathrm{H} 1$ and VPA-histone $\mathrm{H} 1$ mixtures. Variability in the frequency of the band peak assigned to amide I (1640-1623 $\left.\mathrm{cm}^{-1}\right)$ is detected in the curves of drop-casting samples of histone $\left.\mathrm{H} 1 \mathrm{(a}\right)$, and in the curves obtained at the periphery (b) and center ( $c, e)$ of the hemispheres formed after drying of the drops of the $20 \mathrm{mM}$ VPA-histone $\mathrm{H} 1 \mathrm{mixture}(\mathrm{b}, \mathrm{c})$ and the $40 \mathrm{mM}$ VPA-histone $\mathrm{H} 1$ mixture $(\mathrm{d}, \mathrm{e})$. Variability is also observed in the band peak frequency assigned to amide II $(1529-1527 \mathrm{~cm}-$ $\left.{ }^{1}\right)$ when obtained at the center of the hemispheres formed after drying of the drops containing the 20 mM VPA-histone H1 mixture (b). In a-e, a band peak element (shoulder) is suspected at the $1548-1546 \mathrm{~cm}^{-1}$ spectral region.

a

\section{Absorbances}

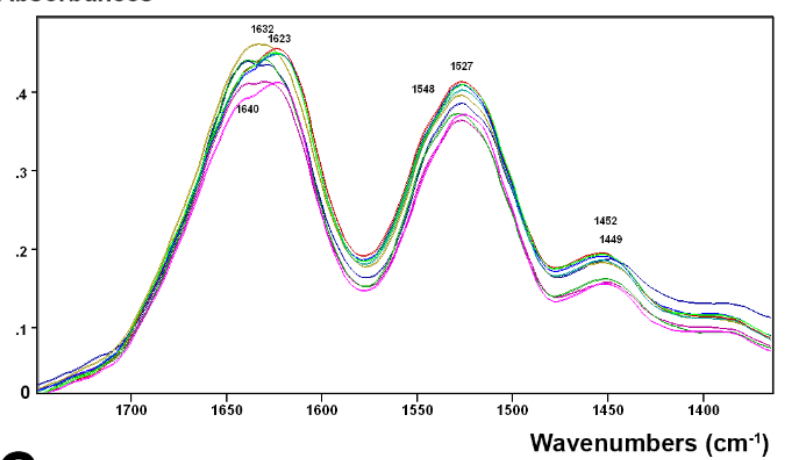

C

Absorbances

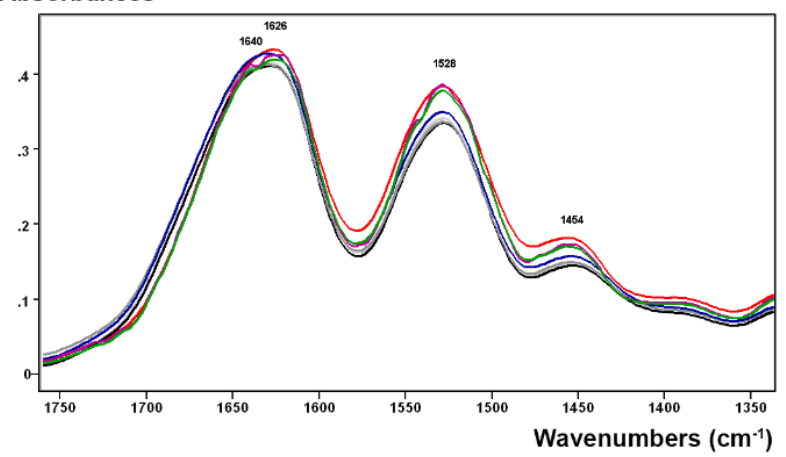

b

Absorbances

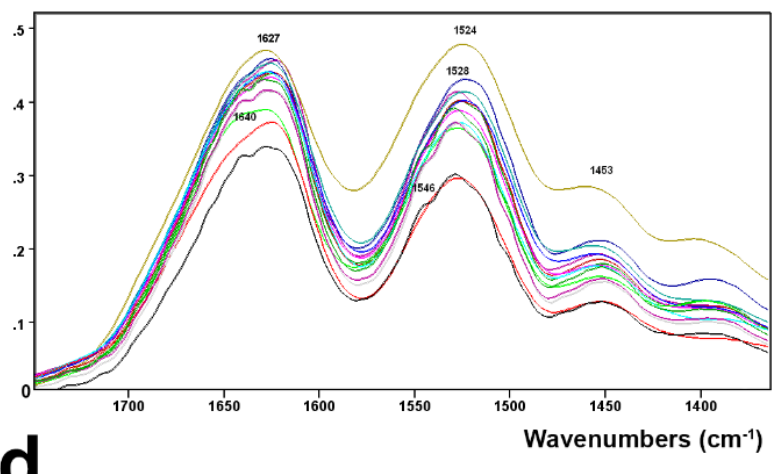

Absorbances

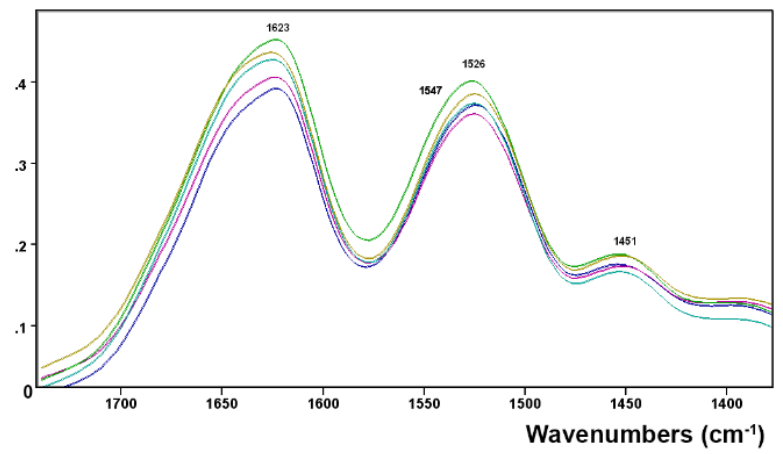

e

Absorbances

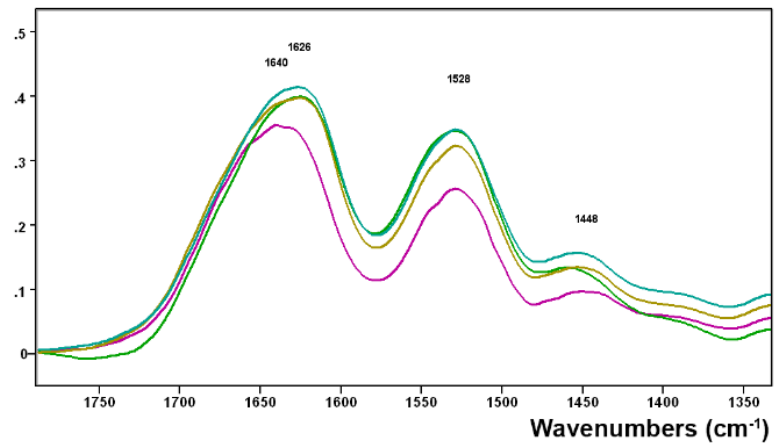


Figure 3. Raw FTIR spectral curves of histone $\mathrm{H} 1$ and VPA-histone $H 1$ mixtures. Details at the $\sim 1350-800 \mathrm{~cm}^{-1}$ spectral range are shown for curves of histone $\mathrm{H} 1(\mathrm{a})$ and at the periphery $(\mathrm{b}, \mathrm{d})$ and center $(\mathrm{c}, \mathrm{e})$ of hemispheres formed from dried drops of $20 \mathrm{mM}$ VPA- $(\mathrm{b}$, c) and $40 \mathrm{mM}$ VPA-histone $\mathrm{H} 1$ mixtures (d, e).

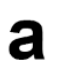

Absorbances

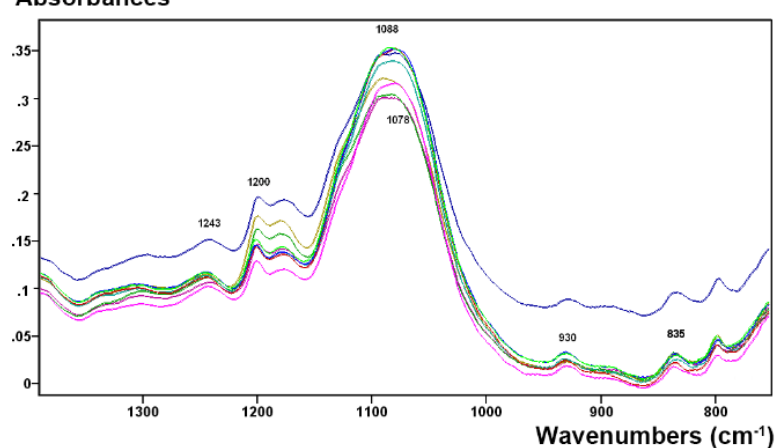

C

Absorbances

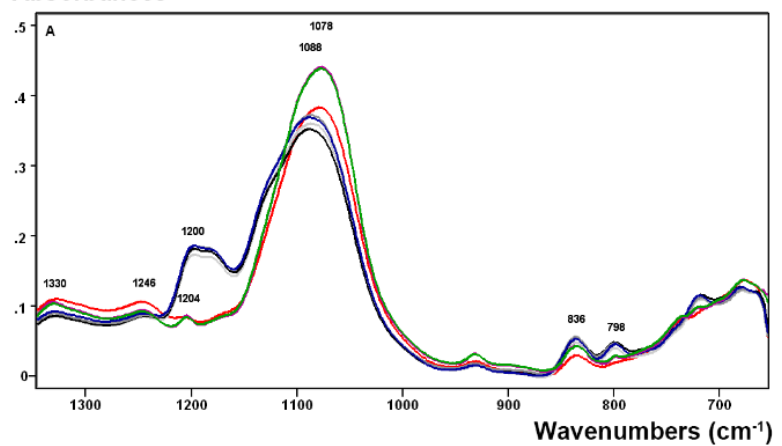

b

\section{Absorbances}

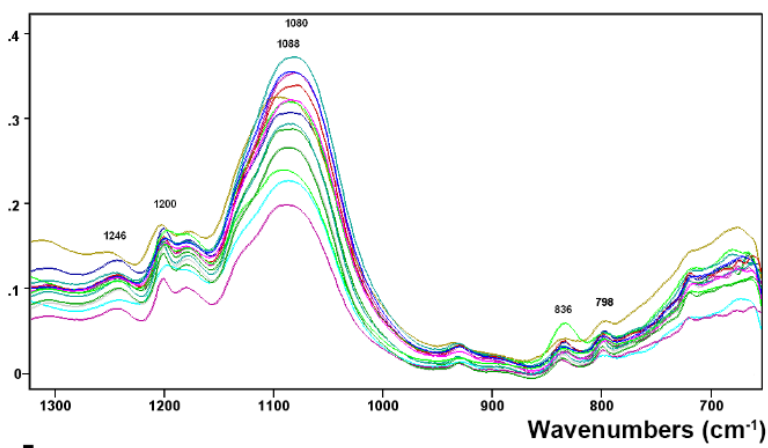

d

Absorbances

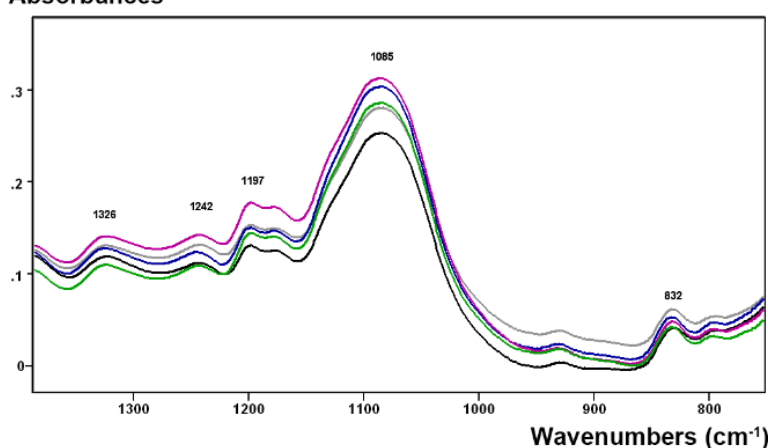

e

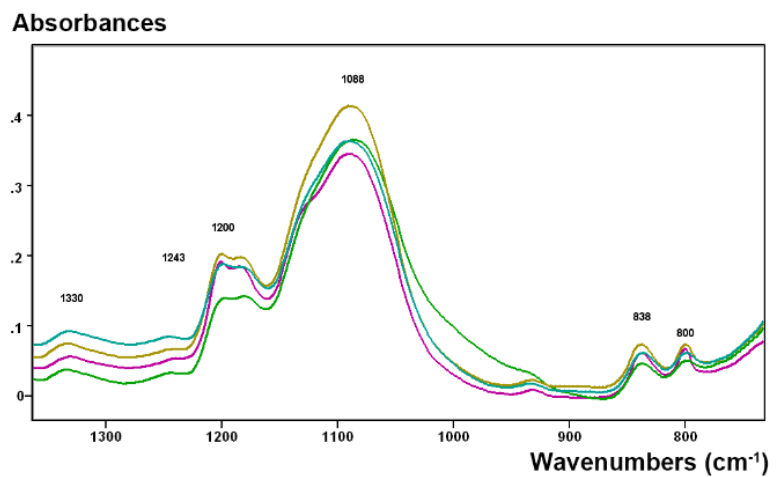


Figure 4. Raw FTIR spectral curves of histone $\mathrm{H} 3$ and VPA-histone $\mathrm{H} 3$ mixture at the $1750-1350 \mathrm{~cm}^{-1}$ spectral range. The curves were obtained at drop-casting samples of histone $\mathrm{H} 3$ (a) and at the periphery (b) and center (c) of hemispheres formed from dried drops of a $20 \mathrm{mM}$ VPA-histone H3 mixture. Variability in the frequency of the band peaks assigned to amide I $\left(1626-1623 \mathrm{~cm}^{-1}\right)$ and amide II $\left(1535-1521 \mathrm{~cm}^{-1}\right)$ is observed.

\section{a}

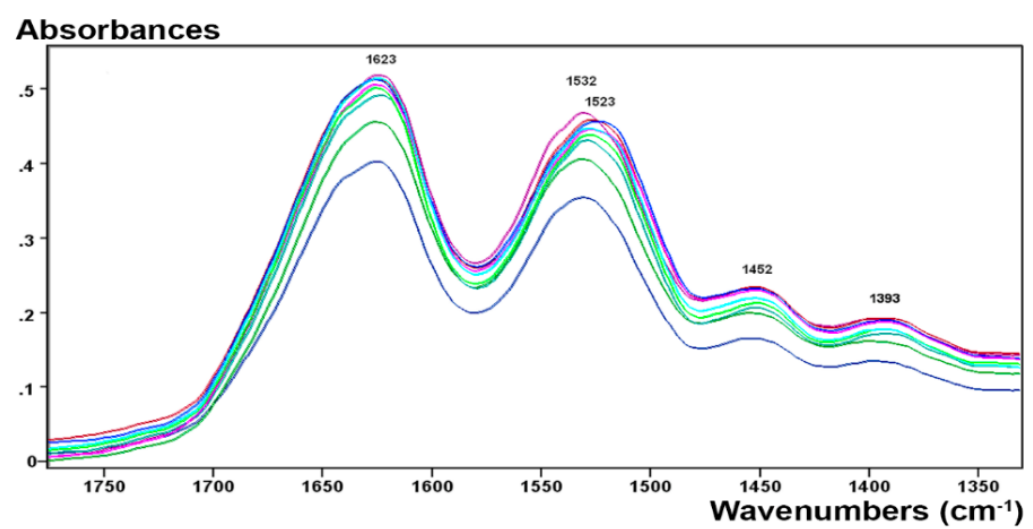

b

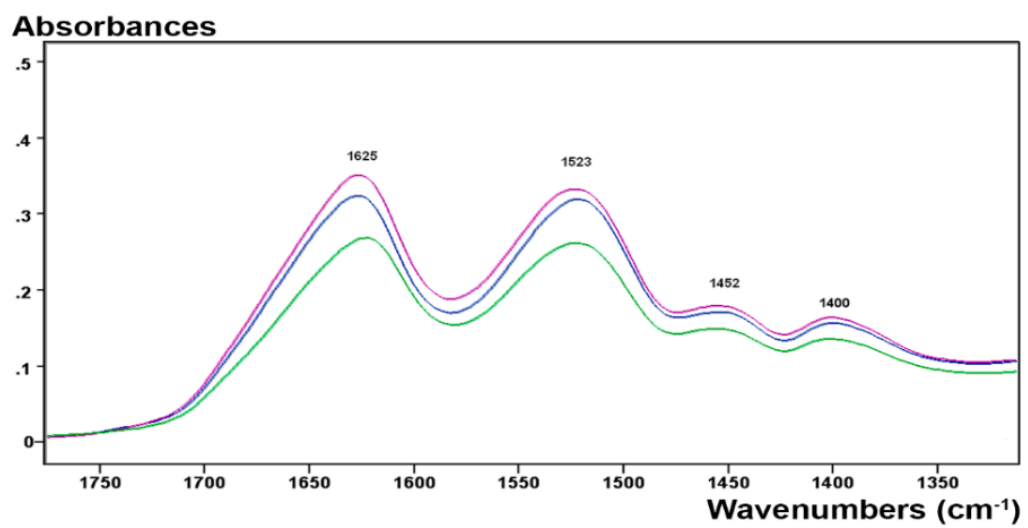

C Absorbances

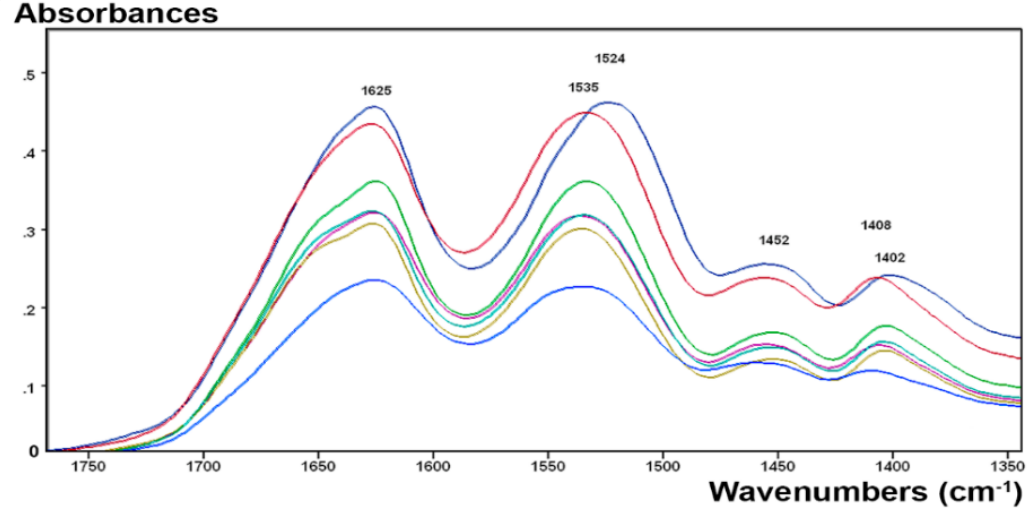

In Tables 1 and 2, comparison of the absorbance values of band peaks assigned to amide groups is shown between the spectra of the VPA-histone $\mathrm{H} 3$ mixture and respective histone control. These data were obtained in the peripheric and central areas of the preparations which consisted of dried drop hemispheres dripped on glass slides. 
Table 1. Absorbance values for the amide A and I band peaks calculated from raw FTIR spectra for dried drops of 20 mM VPA-histone H3 mixtures.

\begin{tabular}{|c|c|c|c|c|c|c|c|}
\hline \multirow{2}{*}{ Samples } & \multirow{2}{*}{$\mathbf{n}$} & \multicolumn{3}{|c|}{ Amide $\mathrm{A}$ absorbances } & \multicolumn{3}{|c|}{ Amide I absorbances } \\
\hline & & $x$ & $\mathbf{S}$ & Md & $\mathbf{x}$ & $\mathbf{S}$ & Md \\
\hline Histone H3 & 8 & 0.2206 & 0.0174 & $0.2166 * \diamond$ & 0.4893 & 0.0406 & $0.5086 * \diamond$ \\
\hline $\begin{array}{c}\text { Histone H3 + VPA } \\
\text { (hemisphere periphery) }\end{array}$ & 3 & 0.1692 & 0.0138 & $0.1698^{*}$ & 0.3154 & 0.0405 & $0.3243^{*}$ \\
\hline $\begin{array}{c}\text { Histone H3 + VPA } \\
\text { (hemisphere center) }\end{array}$ & 7 & 0.1626 & 0.0230 & $0.1583 \diamond$ & 0.3498 & 0.0764 & $0.3231 \diamond$ \\
\hline
\end{tabular}

$*, \diamond$, differences significant at the $\mathrm{P}_{0.05}$ level (Mann-Whitney test); Md, median; $n$, number of spectral curves; $S$, standard deviation; $\mathrm{X}$, arithmetic means.

Table 2. Absorbance values for the amide II and III band peaks calculated from raw FTIR spectra for dried drops of 20 mM VPA-histone H3 mixtures.

\begin{tabular}{|c|c|c|c|c|c|c|c|}
\hline \multirow{2}{*}{ Samples } & \multirow{2}{*}{$\mathbf{n}$} & \multicolumn{3}{|c|}{ Amide II absorbances } & \multicolumn{3}{|c|}{ Amide III absorbances } \\
\hline & & $\mathbf{X}$ & $\mathbf{S}$ & Md & $\mathbf{X}$ & $\mathbf{S}$ & Md \\
\hline Histone H3 & 8 & 0.4335 & 0.0367 & $0.4449 *$ & 0.1637 & 0.0175 & $0.1681 * \diamond$ \\
\hline $\begin{array}{c}\text { Histone H3 + VPA } \\
\text { (hemisphere periphery) }\end{array}$ & 3 & 0.3052 & 0.0382 & $0.3210^{*}$ & 0.1092 & 0.0112 & $0.1157^{*}$ \\
\hline $\begin{array}{c}\text { Histone H3 + VPA } \\
\text { (hemisphere center) }\end{array}$ & 7 & 0.3496 & 0.0832 & 0.3210 & 0.1105 & 0.0327 & $0.1030 \diamond$ \\
\hline
\end{tabular}

$*, \diamond$, differences significant at the $\mathrm{P}_{0.05}$ level (Mann-Whitney test); Md, median; $\mathrm{n}$, number of spectral curves; $\mathrm{S}$, standard deviation; $\mathrm{X}$, arithmetic means.

\section{Data set}

The dataset deposited in the repository of the University of Campinas (https://doi.org/10.25824/redu/OSK2UP) shows infrared microspectroscopical absorbances (FTIR) that permit construction of spectral signatures like those shown in Figures 1-4 of this study and statistical analysis like that shown in Tables 1 and 2 of this study. The dataset comprises nine tables detailing in each of their columns, infrared absorbance values estimated at wavenumbers (in $\mathrm{cm}^{-1}$ ) concerned with the spectral windows for amide A, I, II, and III bands obtained for dried preparations of histones $\mathrm{H} 1$ and $\mathrm{H} 3$ and mixtures of these histones with VPA. Absorbances at wavenumbers assigned to $\mathrm{V}_{\text {as }} \mathrm{C}=\mathrm{O}$ groups and $\mathrm{C}-\mathrm{O}$ stretching were plotted for histone $\mathrm{H} 1$ and VPAhistone $\mathrm{H} 1$ mixtures.
The absorbances concerned with the amide $A$ band for the histone $\mathrm{H} 3$ and the $20 \mathrm{mM}$ VPAhistone $\mathrm{H} 3$ mixture were plotted at the wavenumbers $3283,3277,3275,3273,3271$, $3269,3267,3266,3265,3264,3263,3261$ and $3259 \mathrm{~cm}^{-1}$. Regarding the amide I band for the histone $\mathrm{H} 1$ and the $20 \mathrm{mM}$ and $40 \mathrm{mM}$ VPAhistone $\mathrm{H} 1$ mixtures, the absorbances were plotted at 1640, 1626 and $1623 \mathrm{~cm}^{-1}$, and for the histone $\mathrm{H} 3$ and the $20 \mathrm{mM}$ VPA-histone $\mathrm{H} 3$ mixture, at 1626, 1625, 1624 and $1623 \mathrm{~cm}^{-1}$. The absorbances concerned with the amide II band for the histone $\mathrm{H} 1$ and the $20 \mathrm{mM}$ and $40 \mathrm{mM}$ VPAhistone $\mathrm{H} 1$ mixtures were plotted at the wavenumbers 1536, 1526, 1524 and $1350 \mathrm{~cm}^{-1}$, and those for the histone $\mathrm{H} 3$ and the $20 \mathrm{mM}$ VPAhistone mixture were plotted at 1536, 1535, 1534, 1533, 1531, 1530, 1529, 1527, 1524, 1523, 1521 
and $1516 \mathrm{~cm}^{-1}$. The absorbances concerned with the amide III band for the histone $\mathrm{H} 3$ and the 20 mM VPA-histone H3 mixture were evaluated at the wavenumbers $1259,1258,1254,1253,1251$, $1250,1247,1246$ and $1245 \mathrm{~cm}^{-1}$.

The absorbances assigned to $v_{a s} \mathrm{C}=\mathrm{O}$ groups for the histone $\mathrm{H} 1$ and the $20 \mathrm{mM}$ and $40 \mathrm{mM}$ VPAhistone $\mathrm{H} 1$ mixtures were evaluated at 1550 and $1546 \mathrm{~cm}^{-1}$, and those assigned to C-O stretching for the same samples were evaluated at 1090, 1088 and $1080 \mathrm{~cm}^{-1}$. Absorbances estimated at
2960, 2934, 2931, 2871, 1550, 1546, 1415, 1380 and $1360 \mathrm{~cm}^{-1}$ were also plotted for dried drops of VPA (control).

The columns presented in Tables 1 and 2 of this work identify arithmetic means and respective standard deviations and medians calculated from the absorbances concerned with the amide A, I, II, and III band peaks for histone $\mathrm{H} 3$ (control) and VPA-histone $\mathrm{H} 3$ mixtures identified in the Tables $6,7,8$, and 9 , respectively, of the dataset.

\section{SUPPLEMENTARY MATERIALS}

Repository name: REDU, University of Campinas

DOI of the dataset (when available): DOI:10.25824/redu/OSK2UP

Link to access the data: https://doi.org/10.25824/redu/OSK2UP

\section{ACKNOWLEDGEMENTS}

This work was supported by the São Paulo state Research Foundation (FAPESP, Brazil; grant no. 2015/10356-2) and the Brazilian National Council for Research and Development (CNPq; grants no. 304668/2014-1 and 421299/2018-5). The funders had no role in study design, data collection and analysis, decision to publish or preparation of the manuscript. The authors thank Mr. E.H.M. dos Anjos for assistance with formatting of the figures.

\section{REFERENCES}

DEEGAN, R.D. et al. Capillary flow as the cause of ring stains from dried liquid drops. Nature 389:827-829, 1997. DOI: https://doi.org/10.1038/39827.

VIDAL, B.C.; MELLO, M.L.S. Sodium valproate (VPA) interactions with DNA and histones. Int J Biol Macromol 163:219-231, 2020. DOI: 10.1016/j.ijbiomac.2020.06.265. 